— необходимо производить анализ состава и структуры дебиторской и кредиторской задолженности по конкретным поставщикам и покупателям.

— внедрить на предприятии бухгалтерских программных продуктов[4].

$$
* * *
$$

1. Трудовой кодекс Российской Федерации от 30.12.2001 №197-Ф3 (ред. от 01.04.2019)// http://www.consultant.ru/document/cons_doc_LAW_34683/

2. Потриваева Н.В. Состояние и перспектива учета расчетов по оплате труда: теоретический аспект / Н.В. Потриваева, И.В. Савченко // Экономический форум. - 2014. - No1. - С. 93-98.

3. Бухгалтерский учет учебник для бакалавров / Под ред. Ю.А. Бабаев, А.М. Петров, Л.А. Мельникова. - Москва.: Проспект, $2016 .$.

4. Красова О.С. Бухгалтерский учет производственных запасов [Электронный ресурс]/ Красова О.С.- Электрон. текстовые данные.- Саратов: Медиа, 2009.- 116 с.- Режим доступа: http://www.iprbookshop.ru/967.html .— ЭБС «IPRbooks» .

\title{
Валиева Н.М. \\ Конкуренция как процесс соперничества в развитии банковской системы
}

Таджикский государственный университет права, бизнеса и политики doi: 10.18411/lj-04-2021-88

(Таджикистан, Худжанд)

\section{Аннотация}

Статья посвящена исследованию сущности банковской конкуренции и конкурентоспособности. Проведен обзор теоретических взглядов по вопросу о сущности конкуренции. Изучена структурная организация банковского рынка как специфическая сфера банковской конкуренции. Предложена авторская классификация видов банковской конкуренции. На основании проведенного исследования уточнены сущность и специфика банковской конкуренции и банковской конкурентоспособности.

Ключевые слова: банки, банковская конкуренция, конкурентоспособность, банковский рынок, классификация.

\section{Abstract}

The article is devoted to the study of the essence of banking competition and competitiveness. The review of theoretical views on the issue of the essence of competition is carried out. Studied the structural organization of the banking market as a specific area of banking competition. The author's classification of types of banking competition is proposed. On the basis of the study, the essence and specificity of banking competition and banking competitiveness have been clarified.

Key words: banks, banking competition, competitiveness, banking market, classification.

Изменяющиеся процессы, происходящие в экономике определяют основные тенденции развития банковского рынка и вектор макроэкономических изменений в региональном хозяйственном комплексе, что требует нового институционального решения проблем экономического развития. Конкурентоспособность банковского сектора является одним из важных условий успешного экономического развития государства.

Анализ сущности и специфики банковской конкуренции предполагает прежде всего уточнение наиболее общего понятия «конкуренция». Конкуренция (лат. concurrentia, от лат. concurro - сбегаться, стекаться, совпадать, соответствовать, равняться, быть равным) - это борьба между экономическими субъектами за максимально эффективное использование факторов производства, при единых 
правилах для всех её участников. В экономике говорят о деловой конкуренции хозяйствующих субъектов, каждый из которых своими действиями ограничивает возможность конкурента односторонне воздействовать на условия обращения товаров на рынке, то есть о степени зависимости рыночных условий от поведения отдельных участников рынка. В соответствии с Законом РТ г. Душанбе от 30 мая 2017 года №1417 «О защите конкуренции», конкуренция - соперничество хозяйствующих субъектов, при котором самостоятельными действиями каждого из них исключается или ограничивается возможность каждого из них в одностороннем порядке воздействовать на общие условия обращения товаров на соответствующем товарном рынке.

Конкуренцию рассматривают как процесс соперничества между институтами на рынке [1]. Данный подход основан на понимании конкуренции как состязании в целях достижения лучших результатов и характерен для отечественной экономической литературы.

Анализ приведенных определений позволяет выделить следующие признаки конкуренции:

- существование рынков с альтернативными возможностями выбора для покупателей (продавцов);

- наличие определенного количества покупателей (продавцов), соревнующихся между собой и использующих различные инструменты рыночной политики;

- чередование применения этих инструментов одними конкурентами и ответных мер со стороны других конкурентов.

Таким образом, в общем виде конкуренцию можно определить как соперничество рыночных субъектов, заинтересованных в достижении одной и той же цели. Как известно, цель каждого банка заключается в том, чтобы клиент выбрал и приобрел именно его конкретную услугу.

Ключевая роль в создании эффективной конкурентной среды принадлежит государству, которое обеспечивает необходимую институциональную базу и, прежде всего, законодательство. Такой тезис, на первый взгляд, может показаться не вполне обоснованным, поскольку государственное регулирование и конкуренция часто рассматриваются как антиномии. Однако при углубленном анализе противоречие между задачами государства в рыночной экономике и целями конкуренции в значительной мере снимается в том случае, если государство считает приоритетным не ограничение или свертывание конкуренции, а противодействие недобросовестным формам ее проявления.

Конкуренция в банковской системе сложнее, чем в других секторах экономики [2]. Банковская конкуренция является движущей силой качественных изменений в банковском секторе, направленных на повышение устойчивости кредитных организаций, диверсификацию их деятельности и расширение доступа к финансовым услугам. Ее особенности определяются составом участников, структурой сферы конкуренции, спецификой продукта, формами конкуренции, влиянием на другие сферы экономики и общественной жизни. Специфика банковской деятельности вносит свои особенности непосредственно в процесс банковской конкуренции, что отличает ее от классической конкуренции между товаропроизводителями и дополнительно подтверждает необходимость и важность ее выявления в самостоятельное направление в экономической науке.

В экономической литературе вопрос о банковской конкуренции является спорным, что отчасти связано с отсутствием общепринятого определения понятия «конкуренция».

Исходя из ранее изложенного можно заключить, что банковская конкуренция представляет собой динамичный процесс состязательности коммерческих банков и 
прочих кредитных институтов, в рамках которого они стремятся обеспечить себе прочное положение на рынке банковских услуг. Именно наличие конкуренции вызывает расширение круга предоставленных услуг, регулирование цены на них до приемлемого уровня. Кроме того, конкуренция стимулирует банки к переходу на более эффективные способы предоставления услуг, т. е. обеспечивает обстановку, благоприятную для их развития и совершенствования.

Основные участники банковской конкуренции - это коммерческие банки. Другими достаточно активными участниками являются небанковские кредитные организации нефинансовые организации.

Сферой банковской конкуренции является банковский рынок - сложное образование, имеющее весьма широкие границы и состоящее из множества элементов.

В настоящее время коммерческие банки функционируют в роли продавцов или покупателей практически во всех рыночных секторах.

Следовательно, сфера банковской конкуренции обширна, а конкурентная среда многообразна и разнообразна.

Вынося на рынок тот или иной банковский продукт, коммерческий банк почти всегда сталкивается с конкуренцией не только со стороны других коммерческих банков, но и со стороны небанковских и нефинансовых организаций.

Банковскую конкуренцию нельзя приравнивать к межбанковской конкуренции [6]. Точнее определить это как конкуренцию между всеми участниками банковского рынка. Ни в одном другом секторе экономики нет такого большого и разнообразного состава конкурентов.

Конкуренция стимулирует банки к переходу на более эффективные способы функционирования.

Следует различать понятия «конкурентоспособность коммерческого банка» и «конкурентоспособность предоставляемых им услуг». Если рассматривать понятие «конкурентоспособность» применительно к коммерческому банку, то еe можно определить как возможность эффективной хозяйственной деятельности и ее прибыльной практической реализации в условиях конкурентного рынка. Эта реализация обеспечивается всем комплексом имеющихся у банка средств. Уровень конкурентоспособности услуг является показателем жизнестойкости коммерческого банка и его умения эффективно использовать финансовый, производственный и трудовой потенциалы.

Таким образом, утверждение, что банковская конкурентоспособность - это способность банка предложить услугу, несет в себе неправильное понимание проблемы. Конкурентоспособность банка необходимо рассматривать как динамичный, комплексный показатель сравнительного уровня развития критериев его деятельности, в том числе конкурентоспособности предоставляемых им услуг.

Конкурентоспособность коммерческого банка характеризуется как способность успешно оперировать на конкретном рынке (регионе сбыта) в данный период времени путем разработки и реализации конкурентоспособных услуг. Реализация банковских продуктов и услуг - важнейший вид деятельности любого коммерческого банка. Стратегической целью банка и всех его служб является увеличение прибыли посредством:

- привлечения максимального числа клиентов;

- расширения рынка сбыта своих продуктов и услуг;

- увеличения рыночной доли [5].

Конкурентоспособный банк - это коммерческая организация, обладающая ясным пониманием своих стратегических целей, видением будущего, компетентным персоналом, эффективным механизмом динамичной адаптации к условиям современного мира и требованиям клиентов. Динамичность (как свойство конкурентной организации) требует осуществления инновационной деятельности, 
быстрой оценки ситуации на рынке, быстрого принятия решений и внедрения изменений, непрерывного повышения квалификации кадров.

Таким образом, понятие «конкурентоспособность» можно рассматривать с различных позиций. С одной стороны, конкурентоспособность - это свойство объекта, характеризующее степень удовлетворения конкретной потребности по сравнению с лучшими аналогичными объектами, представленными на данном рынке. С другой стороны, конкурентоспособность - это способность объекта выдерживать конкуренцию в сравнении с аналогичными объектами в условиях конкретного рынка.

Исходя из представленных подходов, можно определить банковскую конкурентоспособность как интегральную характеристику, отражающую потенциальные и реальные возможности банка создавать и продвигать на рынок конкурентоспособные продукты и услуги, отвечающие всем требованиям клиентов, занимать и удерживать устойчивые позиции на рынке банковских услуг. В отличие от дефиниций, имеющихся в экономической литературе, данное определение отражает сложную природу рассматриваемой категории во взаимосвязи ее ключевых аспектов, характеризующих производимые банком услуги, его место на рынке банковских услуг, возможности банка по удержанию позиций на этом рынке.

$$
* * *
$$

1. Алифанов Е.Н., Кочмола К. В. и др. Финан $с$ совая глобализация и развитие банковской системы России: монография / под ред. К. В. Кочмолы. Рос-тов-на-Дону: РГЭУ 2003. С. 218.

2. Банковское дело / под ред. Г. Г. Коробовой. М.: Экономистъ. 2006. С. 53-104, 601-605.

3. Лутошкина Н. К. Банковская конкуренция и конкурентоспособность: сущность, понятие,

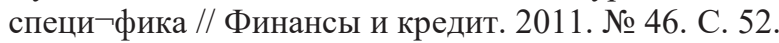

4. Самсонова Е. К. Формирование и развитие конкурентной среды на рынке банковских услуг России: проблемы и перспективы // Финансы и кредит. 2007. № 29. С. 73-76.

5. Тавсиев А. М, Ребельский Н. М. Конкуренция в банковском секторе России: учеб. пособ. для вузов / под. ред. А. М. Тавсиева. М.: ЮНИТИ-ДАНА. 2001. С. 52.

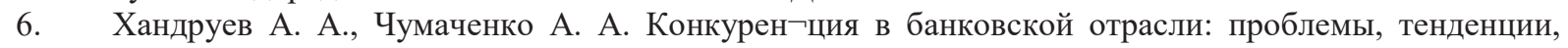
прогнозы // Банковсое дело. 2010. № 11. С. 7.

\section{Измалкова И.В., Павлова А.И. \\ Бухгалтерские риски в деятельности предприятия: сущность, методы, оценки и пути их снижения}

Липеиякии филиал Финансового университета при Правительстве РФ

doi: 10.18411/lj-04-2021-89

(Россия, Липеик)

\section{Аннотация}

В данной статье дана характеристика основных видов бухгалтерских рисков для формирования комплекса мероприятий по минимизации и управлению риском.

Ключевые слова: бухгалтерский учёт, конкуренция, бухгалтерский риск, финансовая отчётность, классификация рисков.

\section{Abstract}

This article describes the main types of accounting risks for the formation of a set of measures to minimize and manage risk.

Keywords: accounting, competition, accounting risk, financial reporting, risk classification.

За последнее десятилетие воздействие бухгалтерского учета на экономику развитых государств начало важно возрастать. Высококачественное внедрение (В.В., Риски в бухгалтерском учёте, 2018) бухгалтерского учета позитивно воздействует не только на финансовой защищенности организации или же государства в целом, но и на 